\title{
Survival of twenty-two months in a patient with primary plasma cell leukaemia treated with melphalan and prednisolone
}

\author{
James D. Walker and Richard S. Kaczmarski \\ Chelmsford Hospitals, Chelmsford, Essex, UK.
}

\begin{abstract}
Summary: In the majority of cases plasma cell leukaemia is a rapidly fatal disease with a mean survival time of five months. There have been reports of increased survival using various regimens of chemotherapy although most cases eventually relapse.

We describe a patient with primary plasma cell leukaemia who responded to a combination of oral melphalan and prednisolone with control of the disease in the bone marrow but relapsed with extramedullary disease in the central nervous system and testes, and died 22 months after diagnosis.

Melphalan poorly penetrates the central nervous system and its testicular penetration is unknown.
\end{abstract}

\section{Introduction}

Plasma cell leukaemia as defined by an absolute plasma cell count of greater than $2 \times 10^{9} /$ litre in the peripheral blood or more than $20 \%$ of the peripheral leucocytes as plasma cells ${ }^{1}$ may occur in patients already suffering from multiple myeloma (about $2 \%$ will develop this complication) or may be the first presentation of a plasma cell malignancy, so-called primary plasma cell leukaemia. This is a rare condition with 49 cases reported between 1965 and $1980 .^{1}$ The mean survival time between diagnosis and death is 4.9 months, although three complete remissions have been reported. ${ }^{1,5,6}$

A number of treatment regimens have been suggested,1,2,5-16 including the conventional therapy for multiple myeloma of melphalan and prednisolone, ${ }^{2,6,7,15,17,18,26}$ but no single regimen has yielded consistent remissions.

We describe a patient with primary plasma cell leukaemia treated with cyclical courses of oral melphalan and prednisolone effecting control of the disease in the bone marrow and an initial excellent clinical response, only to relapse with leukaemic deposits in his testes and central nervous system 14 months after diagnosis. At that time there was no objective evidence of active disease in the bone marrow.

Correspondence: J.D. Walker, B.Sc., M.R.C.P., Unit for Metabolic Medicine, UMDS - Guy's Campus, 4th Floor, Hunts House, London Bridge, London SEl 9RT, UK.

Accepted: 20 October 1987
In this case the central nervous system and testes may have acted as sanctuary sites from the effect of the chemotherapy as is seen in cases of acuteo lymphoblastic leukaemia in children. ${ }^{23}$

\section{Case report}

In November 1984 a 62 year old Caucasian male was admitted with a 6 week history of lethargy, weakness and dyspnoea on exertion. On examination he was clinically anaemic with no other abnormalities.

Investigations revealed: haemoglobin $7.8 \mathrm{~g} / \mathrm{dl}$, MCV $95.7 \mathrm{fl}$, white cell count $13.8 \times 10^{9} / 1$, neutrophils $19 \%$, lymphocytes $39 \%$, monocytes $1 \%$, eosinophils $2 \%$, plasma cells $38 \%$, platelets $100 \times 10^{9} / 1$. The erythrocyte sedimentation rate was $146 \mathrm{~mm} / \mathrm{h}$. There was a monoclonal IgG ((lambda) serum paraprotein $(52 \mathrm{~g} / \mathrm{l})$ with lambda BenceJones proteinuria. Blood urea and calcium, and skeletal X-rays were normal.

Bone marrow examination from a sternal aspirate revealed a hypercellular marrow virtually replaced by sheets and clumps of plasma cells some of which were well differentiated but many were larger and primitive. Erythropoeisis and myelopoeisis were both very depressed and only an occasional megakaryocyte was identified.

The initial management consisted of a blood transfusion, allopurinol $300 \mathrm{mg} /$ day and courses of melphalan $15 \mathrm{mg} /$ day and prednisolone $45 \mathrm{mg}$ /day

(C) The Fellowship of Postgraduate Medicine, 1988 
for 5 days every 3 weeks. He made an excellent clinical, haematological and biochemical response After eight courses of treatment the interval between courses was increased to three months and he received a final course in March 1986, when the serum IgG concentration was $6.9 \mathrm{~g} / 1$ and his marrow contained $3 \%$ plasma cells.

In December of 1985 he suffered a vitreous haemorrhage destroying the sight of his right eye and in February 1986 he gave a 5 week history of tenderness and swelling of the testes. Biopsies revealed testicular tissue replaced by plasma cells and he underwent bilateral orchidectomy.

In April 1986 he gave a 2 week history of deteriorating hearing and on examination he had bilateral neuronal deafness, bilaterally decreased corneal reflexes and a left lower motor neurone seventh nerve lesion. Examination of his cerebrospinal fluid revealed bloodstained fluid and a protein content of $800 \mathrm{mg} / \mathrm{dl}$. Plasma cells were seen and an IgG paraprotein was isolated. A computed tomographic (CT) brain scan showed multiple enhancing deposits in both cerebral hemispheres (Figure 1).

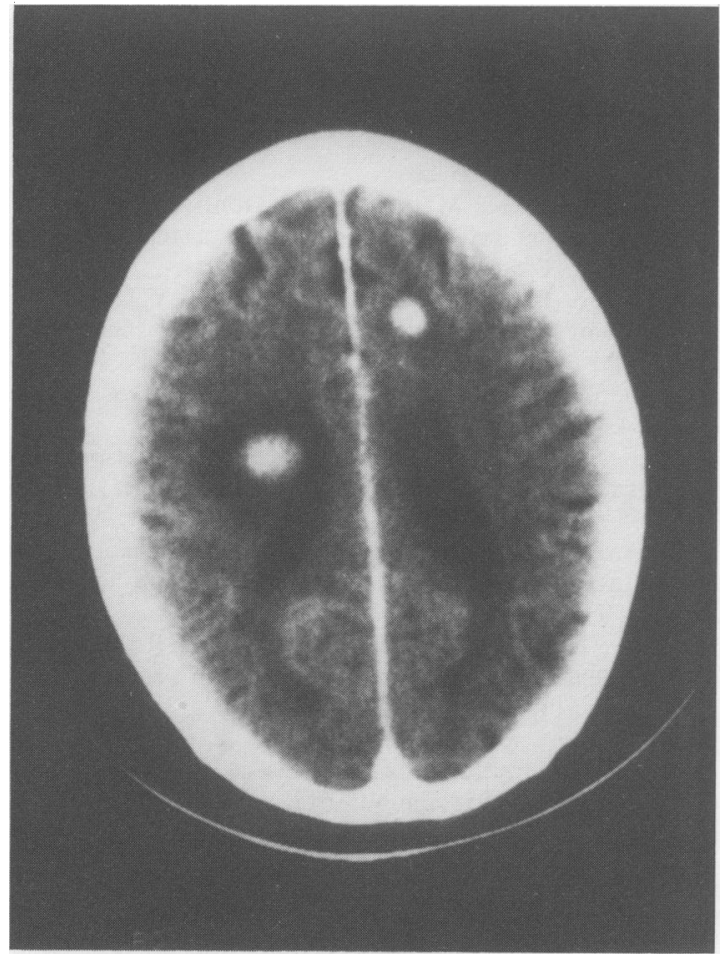

Figure 1 Computerized axial tomogram demonstrating intra-cerebral tumour deposits. Abnormal plasma cells and the IgG paraprotein were isolated from the cerebrospinal fluid.
He received methyl prednisolone $1.5 \mathrm{~g} /$ day intravenously for 5 days with no clinical or CT improvement. $\mathrm{He}$ was given carmustine (BiCNU) $300 \mathrm{mg}$ intravenously with no clinical improvement.

He died in September 1986, twenty-two months after diagnosis, following the development of retinal and subcutaneous deposits.

\section{Discussion}

Generally plasma cell leukaemia is rapidly fatal but there have been previous reports of a useful response to combinations of chemotherapeutic regimens.

Shaw et al. ${ }^{16}$ obtained a good partial response following a regimen of cyclophosphamide, vincristine, cytosine arabinoside and prednisolone (COAP) and later high dosage melphalan and prednisolone. Their patient survived for 13 months and Lishner et al. ${ }^{8}$ using COAP achieved a survival of 22 months.

Cyclophosphamide ${ }^{12,14}$ alone, or in combination with prednisolone ${ }^{12,13}$ has effected survival of up to 4 years and in one case doxorubicin successfully controlled subcutaneous tumour. nodules. In our patient general debility precluded this being used. McElwain and Powles ${ }^{6}$ using high dose intravenous melphalan achieved a complete remission and their patient had a subsequent autograft of his remission bone marrow and one patient treated with ${ }^{32} \mathrm{P}$ had a prolonged remission only to die 12 years later in an accident. $^{2}$

Generally the response of plasma cell leukaemia to conventional myeloma therapy of prednisolone and melphalan has been poor ${ }^{7,12}$ and only occasional remissions with this therapy have been reported. Pruzanski ${ }^{7}$ reported a patient surviving two years and Woodruff ${ }^{12}$ a patient surviving 28 months, but most remissions, if they occur, are short lived, ${ }^{15,18,26}$ with a mean of 9 months.

The reason why certain patients respond to chemotherapy are not clear but it may be due to the degree of differentiation of the plasma cells. ${ }^{1}$ If one accepts that the tumour grows exponentially a rapid response to treatment is a poor prognostic sign, ${ }^{27}$ in that patients with multiple myeloma who showed a rapid response to treatment relapsed quickly and at two years after diagnosis only $39 \%$ survived compared to $78 \%$ surviving at two years who had shown a slow response. This may explain the reason for and nature of the relapse in this case.

There is good evidence from the bone marrow samples, peripheral blood counts and immunoglobulin levels that the treatment significantly reduced the tumour mass in the bone marrow, however there must have been at least as many 
residual tumour cells in the bone marrow as seen in other acute leukaemias in remission. Similarly small numbers of tumour cells, not recognized in routine differential counts, may well have continued to circulate and these cells may have become trapped or homed-into the so-called sanctuary sites of the testes and central nervous system. These are recognized sites for deposits of plasma cell leukaemia $9,12,17,28,32$ and may occur despite a good clinical and haematological response to treatment. $9,11,17$

There is an anatomical blood-brain barrier which is poorly penetrated by the use of intravenous melphalan $19,20,21,22$ and results in the brain acting as a sanctuary from chemotherapeutic attack. In acute lymphoblastic leukaemia specific measures are taken to attempt to control the disease process in the central nervous system. The response to local radiotherapy of intracerebral myelomatous deposits has been helpful ${ }^{31}$ but intrathecal methotrexate previously failed to control deposits of plasma cell leukaemia in the brain. ${ }^{12}$

\section{References}

1. Osanto, S., Müller, H.P., Schmit, H.R.E., Van Nieuwkuup, J.A. \& Willemze, R. Primary plasma cell leukaemia. A case report and a review of the literature. Acta Haematol 1983, 70: 122-129.

2. Kyle, R.A., Maldonado, J.E. \& Bayrd, E.D. Plasma cell leukaemia. Report on 17 cases. Arch Intern Med 1974, 133: 813-818.

3. Bichel, J. et al. Leukaemic myelomatosis (plasma cell leukaemia): A review with report of four cases. Acta Radiol (Stockh) 1952, 37: 196-207.

4. Creyssel, R. et al. Etude immunochimique de 463 serums contenant une paraproteine. In: Peeters, $\mathrm{H}$. (ed) Protides of the Biological Fluids (Proceedings of the Eleventh Colloquim, Bruges 1963). Elsevier Publishing, Amsterdam, 1964, pp 97-99.

5. Bayrd, E.D. Sustained remission in multiple myeloma. Blood 1955, 10: 662.

6. McElwain, T.J. \& Powles, R.L: High-dose intravenous melphalan for plasma-cell leukaemia and myeloma. Lancet 1983, ii: 822-824.

7. Pruzanski, W., Platts, M.R. \& Ogryzlo, M.A. Leukaemic form of immunocytic dyscrasia (plasma cell leukaemia). A study of ten cases and review of the literature. $A J$ Med 1969, 47: 60-74.

8. Lishner, M., Lang, R., Jutrin, I. \& Ravid, M. Favourable response to aggressive chemotherapy in a patient with primary plasma cell leukaemia. Acta Haematol 1985, 74: 49-51.

9. Andaloro, V.A. \& Babott, D. Testicular involvement in plasma-cell leukaemia. Urology 1974, III: 636-638.

10. Pacilli, L., Ferraro, P., Coctri, S., DeLaurenzi, A. Plasma cell leukaemia: a report on three patients. Tumori 1983, 69: 589-591.
It has been suggested that the lowered temperature of the testes in the scrotum creates a non-anatomical blood-testes barrier making this organ a sanctuary from chemotherapeutic attack and penetration of melphalan into the testes is unknown (personal communication, Wellcome Foundation). The treatment for plasma cell leukaemia deposits in the testes has been surgical. ${ }^{9}$

Achieving a response in plasma cell leukaemia with conventional therapy of melphalan and prednisolone is rare but if this occurs, extramedullary relapses especially in sites protected from chemotherapeutic attack should be anticipated.

\section{Acknowledgements}

We are grateful for the advice of Professor J.S. Malpas in the management of the intracerebral deposits. We would like to thank Mrs L. Forrest for her secretarial help.

We thank Dr H.-J.B. Galbraith for allowing us to report this case.
11. Brumana, N., Grampa, A., Oldrini, R., Parravicini, U. \& Salmini, G. Multiple myeloma and plasma cell leukaemia; two different diseases. Haematologica (Pavia) 1985, 1: 85-86.

12. Woodruff, R.K., Malpas, J.S., Paxton, A.M. \& Lister, T.A. Plasma cell leukaemia (PCL): a report on 15 patients. Blood 1978, 52: 839-845.

13. Otsuka, T., Kimura, N., \& Niho, Y. Multiple myeloma terminating in the leukaemic stage with lobular nucleated eccentric plasma cells: a good response to therapy. Nippon Ketsueki Gakkai Zasshi 1984, 47: 150-157.

14. Anderson, J. \& Osgood, E.E. Acute plasmacytic leukaemia responsive to cyclophosphamide. JAMA 1965, 193: 188-190.

15. Ogawa, M., Kuchwa, S. Smith, C., Ishizaka, K. \& McIntyre, O.R. Clinical aspects of IgE myeloma. $N$ Engl J Med 1969, 281: 1217-1220.

16. Shaw, M.T., Twele, T.W. \& Nordquist, R.E. Plasma cell leukaemia; detailed studies and response to therapy. Cancer 1974, 33: 619-625.

17. Zawadzki, Z.A., Kapaclia, S. \& Barnes, A.E. Leukaemic myelomatosis (plasma cell leukaemia). Am J Clin Pathol 1978, 70: 605-611.

18. Gailani, S., Seon, B.K. \& Henderson, E.S. Plasma cell leukaemia: response to conventional myeloma therapy. J Med 1977, 8: 403-414.

19. Lazarus, H.M., Herzig, R.H., Pole-Graham, J. et al. Intensive melphalan chemotherapy and cryopreserved autologous bone marrow transplantation for the treatment of refractory cancer. J Clin Oncol 1983, 1: 359-367.

20. Adriet, C., Tranchand, P., Biron, P., Rebattu, P. \& 
Philip, T. Pharmacokinetics of high dose melphalan in children and adults. $B r J$ Cancer 1985, 52: 446.

21. Gouyette, A., Hartmann, O. \& Pico, J-L. Pharmacokinetics of high dose melphalan in children and adults. Cancer Chemother Pharmacol 1986, 16: 184-189.

22. Ardiet, C., Tranchand, B., Biron, P., Rebattu, P. \& Philip, T. Pharmacokinetics of high-dose intravenous melphalan in children and adults with forced diuresis. Cancer Chemother Pharmacol 1986, 16: 300-305.

23. Pinkel, D. Current issues in the management of children with acute lymphocytic leukaemia. Postgrad Med J 1985, 61: 93-102.

24. Hino, S. Plasmocytic myelomatosis in Japan. Bull Tokyo Med Dent Univ 1956, 2: 217-234.

25. Bayrd, E.D. \& Hall, B.E. Unusual remission after radiophosphorus therapy in a case of 'acute plasma cell leukaemia'. Blood 1948, 3: 1019-1024.

26. Toma, V.A., Retief, F.P., Potgieter, G.M. \& Anderson, J.D. Plasma cell leukaemia. Diagnostic problems in our experience with 11 cases. Acta Haematol 1980, 63: 136-145.
27. Hobbs, J.R. Growth rates and responses to treatment in human myelomatosis. $\mathrm{Br} J$ Haematol 1969, 16: 607-617.

28. Martin, C., Orburch, S., De Pizwlatto, M.B., Fuchs, C.R., Battilare, N. \& Pinto, M.T. Mieloma de BenceJones con derrame pleural bilateral y leucemia de celulas plasmaticas. Sangre 1982, 4: 558-563.

29. Van Eys, J. \& Sullivan, M.P. Testicular leukaemia and temperature. Lancet 1976, ii: 256-257.

30. Nesbitt, M.E., Santher, H., Robinson, L.L. et al. Sanctuary therapy. A randomized trial of 724 children with previously untreated acute lymphoblastic leukaemia. Cancer Research (Baltimore) 1982, 42: 674 680.

31. Weiner, L.P., Anderson, P.N. \& Allen, J.C. Cerebral plasmacytoma with myeloma protein in the cerebrospinal fluid. Neurology 1966, 26: 615-618.

32. Newman, W., Diefenback, C., Quinn, M. \& Myer, L. A case of acute plasma cell leukaemia supporting the concept of unity of plasma cellular neoplasia. Cancer 1952, 5: 514 . 